\title{
Epistemology engines
}

\section{An antique optical device has powered several centuries of scientific thought.}

\section{7}

Don Ihde

he increasing popularity of the term 'technoscience' as a description of the relations between science and technology is also suggestive of other ways in which science and technology are entwined. Historians of science have a saying: "Science owes more to the steam engine than the steam engine owes to science." Historically, the steam engine developed without much explicit use of scientific theory; yet it inspired the ideas of entropy and the second law of thermodynamics. The machine, not raw nature, suggested the phenomena.

The steam engine shows how a technology can serve as a partial 'epistemology engine'. But a nearly forgotten optical device from early modern science gives a much fuller model for how knowledge itself is produced, a true epistemology engine. This is the camera obscura, which later evolved into the pinhole camera. The optical effect in which some external scene, under light, could be seen as an inverted image inside a darkened room on a blank screen, may have been known to Euclid, but it was clearly described by the Islamic philosopher Alhazen, in his Optics of 1037.

Camera obscuras, and related camera lucidas, became well known in the Renaissance: in about 1430, Leon Battista Alberti used them to trace objects with astonishing verisimilitude; the camera contributed to the development of perspective drawing. The optical effect also automatically reduced three dimensions to two. Leonardo da Vinci again described the darkroom (in about 1450) and explicitly made the camera a model for the eye: "when the images of illuminated bodies pass through a small hole into a dark room ... you will see on the paper all those bodies in their natural shapes and colors, but they will appear upside down and smaller ... the same happens inside the pupil."

But the camera did not become a full epistemology engine until both René Descartes and John Locke explicitly made it thus in the seventeenth century. Descartes in La Dioptrique and Locke in the Essay on Human Understanding both draw upon the camera obscura as a model for how knowledge is produced. For them it is more than the eye that represents the world; the camera is to the eye as the eye is to the mind. Locke's analogues are strikingly literal: "external and internal sensation are the only passages I can find of knowledge to the understanding. These are ... the windows by which light is let

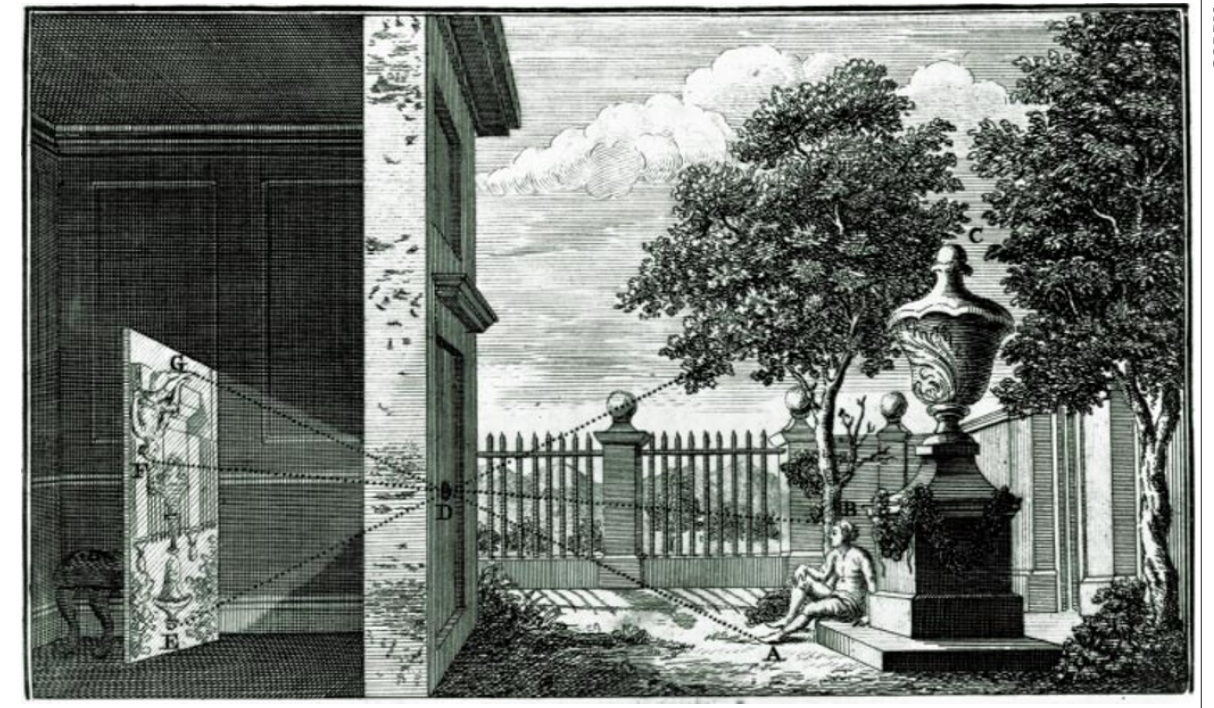

- or Descartes and Locke, the camera obscura is more than the eye that represents the world; it is to the eye as the eye is to the mind.

into this dark room: for methinks the understanding is not much unlike a closet shut from light, with only some little opening left, to let in external visible resemblances, or ideas of things without: ... [these] resemble the understanding of a man, in reference to all objects of sight and the ideas of them."

Here we have the birth of early modern epistemology: 'reality' is 'external', knowledge is 'represented' and 'internal', and 'objective truth' has to be a 'correspondence' between the object and its representation. But with this model of knowledge comes the problem of the inner homunculus or 'subject', the self trapped inside the camera, and the need for an ideal observer who sees both what goes on inside and outside at the same time and is thus able to tell whether the object and its representation correspond. Such is the epistemology produced by the engine of the camera obscura.

This progressive history of an epistemology engine displays two movements associated with it. The first is one of escalation from Alhazen's observation of an optical effect; to da Vinci's camera as analogue for the eye; to Locke's and Descartes' analogue of camera to eye to mind - by which the camera is made into a full epistemology engine. The second is the inward progression of the location where 'external' reality, itself an artefact of the geometry of the imaging phenomenon, interfaces with the 'inner' representation. For da Vinci, the interface of external/internal occurs "in the pupil"; for Descartes, it is the retina; and, still continuing the camera epistemology, contemporary neuroscience locates it in the brain.

As well as being an amazingly persistent epistemology engine, the ghost of this forgotten technology lurks in the 'science wars'. At least one dimension of this contemporary controversy revolves around a passionate defence of notions such as 'external reality', 'truth' usually defined as 'correspondence', which is modernism's form of 'objectivity', and so on. Those who have begun to question this epistemology (and its antique engine) are dubbed postmodernists and relativists, the latter of whom have yet to agree upon or produce a new epistemology engine. Perhaps it is time, however, to explore a wider array of possibilities.

Don Ihde is in the Department of Philosophy, State University of New York, Stony Brook, New York 11794-3750, USA. 